\title{
Investigation into Different Polarimetric Features for Sea Ice Classification Using X-Band Synthetic Aperture Radar
}

\author{
Rudolf Ressel, Suman Singha, Member, IEEE, Susanne Lehner, Member, IEEE, Anja Rösel, \\ and Gunnar Spreen, Member, IEEE
}

\begin{abstract}
Satellite-borne synthetic aperture radar has proven to be a valuable tool for sea ice monitoring for more than two decades. In this study, we examine the performance of an automated sea ice classification algorithm based on polarimetric TerraSAR-X images. In the first step of our approach, we extract 12 polarimetric features from HH-VV dualpol StripMap images. In a second step, we train an artificial neural network, and then, feed the feature vectors into the trained neural network to classify each pixel into an ice type. The first part of our analysis addresses the predictive value of different subsets of features for our classification process (by means of measuring mutual information). Some polarimetric features such as polarimetric span and geometric intensity are proven to be more useful than eigenvalue decomposition based features. The classification is based on and validated by in situ data acquired during the N-ICE2015 field campaign. The results on a TerraSAR-X dataset indicate a high reliability of a neural network classifier based on polarimetric features. Performance speed and accuracy promise applicability for near real-time operational use.
\end{abstract}

Index Terms-Artificial neural network (ANN), feature evaluation, polarimetry, sea ice classification, TerraSAR-X.

\section{INTRODUCTION}

$\mathbf{O}$ VER more than three decades, synthetic aperture radar (SAR) has become an invaluable asset for scientific monitoring of ice infested maritime regions. In contrast to optical imaging, SAR is not impeded by cloud coverage or lack of daylight. While airborne and shipborne SAR cannot always be used during adverse weather conditions, spaceborne SAR image acquisition is not impeded by weather incidents and can cover almost any region on the globe with short revisit times. Given that sea ice coverage appears in remote regions that are otherwise hard to reach, satellites with global coverage are an

Manuscript received June 29, 2015; revised January 25, 2016; accepted February 28, 2016. Date of publication August 01, 2016; date of current version August 12, 2016. This work was supported in part by Echtzeitdienste für die Maritime Sicherheit (EMS) Project and in part by the Norwegian Polar Institute's Centre for Ice, Climate and Ecosystems (ICE) through the N-ICE2015 Project. (Corresponding Author: Rudolf Ressel.)

R. Ressel, S. Singha, and S. Lehner are with the Maritime Safety and Security Lab, Remote Sensing Technology Institute (IMF), German Aerospace Center (DLR), 28199 Bremen, Germany (e-mail: Rudolf.Ressel@dlr.de; Suman.Singha@dlr.de; Susanne.Lehner@dlr.de).

A. Rösel is with the Norwegian Polar Institute (NPI), 9296 Troms $\emptyset$, Norway (e-mail: anja.roesel@npolar.no).

G. Spreen was with Norwegian Polar Institute (NPI), 9296 Troms $\varnothing$, Norway. He is now with the Institute of Environmental Physics, University of Bremen, 28359 Bremen, Germany (e-mail: gunnar.spreen@uni-bremen.de).

Color versions of one or more of the figures in this paper are available online at http://ieeexplore.ieee.org.

Digital Object Identifier 10.1109/JSTARS.2016.2539501 ideal way for any type of monitoring purpose. Satellites such as RADARSAT-1 and 2, ERS, or ENVISAT in C-band and TerraSAR-X (TSX) in X-band have proven the suitability of SAR sensors for investigating sea ice in Arctic and Antarctic regions. The size of SAR images extends up to a few hundred kilometers in width and length. This facilitates wide area investigations, e.g., as conducted for field experiments in the marginal ice zone (ONR MIZ 2015 campaign, see [1]). Topics in sea ice research using SAR are ice drift (see [2]-[6]), sea state and wave propagation into sea ice (see [7] and [8]), ice concentration (see [9]), iceberg detection (see [10] and [11]). Most research published so far on SAR-based sea ice classification concentrates on single polarized data (e.g., [12]-[22]). Such work naturally concentrates on classical image analysis tools. Among such tools are texture analysis via gray level cooccurrence matrices (GLCM), (cf., [12]-[15], [17], [18], [23], and [24]), autocorrelation methods (see [25]), wavelet-based features (see [7] and [26]), Gabor wavelet techniques (see [12]), and Markov random fields (see [16]). However useful and successful these techniques may be, there are still major obstacles in sea ice classification, that remain for all mentioned approaches. Most prominent is the high variability of different ice types by influence of incidence angle, weather conditions, location, and season.

Polarimetric data (i.e., at least two copol channels available) promise to cope better with these obstacles, since each acquisition contains more information than only one SAR channel. The different backscatter behaviors (in different channels) allow for a better characterization of different ice types. When polarimetric data are available, the most straightforward analysis would inspect the intensities and phases of different channels directly (see [27]). Furthermore, it is rather common to investigate parameters based on the eigendecomposition of the scattering matrix like the eigenvalues and components of the eigenvectors (see [28]) or derived quantities like the canonical $\mathrm{H} / \mathrm{A} / \alpha$ parameters (see [28]-[30]). Wakabayashi et al. [28] used this approach on airborne L-band data to investigate characteristics of sea ice types. In other approaches, the distributions of the coherency matrix are computed to be used as input arguments of an unsupervised Wishart classifier (see [31] and [32]). Recent publications (see [33] and [34]) proposed a polarimetric approach based on C-band data in which a segmentation precedes an automated, statistical labeling of the segments. This automated method is then compared with manual segmentations and found to improve the quality of otherwise highly subjective 
TABLE I

TERRASAR-X MAJOR SPECIFICATIONS OF DIFFERENT IMAGING MODES

\begin{tabular}{|c|c|c|c|c|c|c|c|}
\hline \multirow{3}{*}{$\begin{array}{l}\text { Imaging Mode } \\
\text { Polarization Mode } \\
\text { Channels }\end{array}$} & \multirow{3}{*}{$\begin{array}{c}\text { SC } \\
\text { S } \\
\{\mathrm{HH}, \mathrm{VV} \\
\mathrm{HV}, \mathrm{VH}\}\end{array}$} & \multicolumn{2}{|c|}{ SM } & \multicolumn{2}{|c|}{ SL } & \multicolumn{2}{|c|}{ HS } \\
\hline & & $\mathrm{S}$ & $\mathrm{D}$ & $\mathrm{S}$ & $\mathrm{D}$ & $\mathrm{S}$ & $\mathrm{D}$ \\
\hline & & $\begin{array}{l}\{\mathrm{HH}, \mathrm{VV} \\
\mathrm{HV}, \mathrm{VH}\}\end{array}$ & $\begin{array}{l}\{\mathrm{HH} / \mathrm{VV}, \\
\mathrm{HH} / \mathrm{HV}, \\
\mathrm{VV} / \mathrm{HV}\}\end{array}$ & $\{\mathrm{HH}, \mathrm{VV}\}$ & $\{\mathrm{HH} / \mathrm{VV}\}$ & $\{\mathrm{HH}, \mathrm{VV}\}$ & $\{\mathrm{HH} / \mathrm{VV}\}$ \\
\hline Data collection range & \multicolumn{7}{|c|}{$15^{\circ}-60^{\circ}$} \\
\hline Full performance angle & $20^{\circ}-45^{\circ}$ & \multicolumn{2}{|c|}{$20^{\circ}-45^{\circ}$} & \multicolumn{2}{|c|}{$20^{\circ}-55^{\circ}$} & \multicolumn{2}{|c|}{$20^{\circ}-55^{\circ}$} \\
\hline Range scene size [km] & 100 & 30 & 15 & 10 & 10 & 10 & 10 \\
\hline Azimuth scene size $[\mathrm{km}]$ & 150 & 50 & 50 & 10 & 10 & 5 & 5 \\
\hline Abs. Radiometric Accuracy [dB] & 0.7 & 0.6 & 0.6 & n.a. & n.a. & n.a. & n.a. \\
\hline Relative Radiom. Accuracy [dB] & 0.4 & 0.3 & 0.3 & n.a. & n.a. & n.a. & n.a. \\
\hline NESZ [db] & \multicolumn{7}{|c|}{-26 to -19} \\
\hline Incidence Angle $\left({ }^{\circ}\right)$ & 20 to 45 & 20 to 45 & 20 to 45 & 20 to 55 & 20 to 55 & 20 to 55 & 20 to 55 \\
\hline Slant range resolution[m], SSC only & & \multicolumn{2}{|c|}{$\sim 1.2$} & \multicolumn{2}{|c|}{$\sim 1.2$} & $\sim 0.6$ & $\sim 1.2$ \\
\hline Ground range resolution (SE) $[\mathrm{m}]$ & 19.2 to 17.0 & 3.5 to 3.3 & 6.6 & 3.5 to 1.7 & 3.5 to 3.4 & 1.8 to 1.1 & 3.3 to 2.2 \\
\hline Azimuth resolution [m] & 19.2 to 18.5 & 3.5 to 3.3 & 6.6 & 3.5 to 1.7 & 3.5 to 3.4 & 1.8 to 1.1 & 3.3 to 2.2 \\
\hline
\end{tabular}

$\mathrm{S}=$ single pol, $\mathrm{D}=$ dual polarimetric, $\mathrm{SE}=$ spatially enhanced mode.

manual interpretations. For the most part, mentioned publications were concerned with directly relating physical properties of certain ice types to particular polarimetric parameters (and possibly giving physical explanations for observed behavior) and discussed how the generalizability of classifiers is impacted by location, season, and incidence angle. Moen et al. in [33] and [34] qualitatively examined the plausibility of the different outcomes of manual and automatic classification approaches. Our work heads into a slightly different direction as it intends to contribute a comprehensive quantification of the information theoretical qualities of polarimetric parameters $(\mathrm{H} / \mathrm{A} / \alpha)$ and other polarimetric parameters derived from the scattering matrix (see [35]) in X-band. The underlying dataset is a time series of dualpol StripMap images in X-band (TSX), which has not yet been deeply investigated for its potential to classify sea ice. The motivation of our work is concerned with the establishment of an automated sea ice classification algorithm for navigational purposes. Therefore, we assess the information quality of the parameters prior to classification. Instead of directly linking clusters in the parameter space to certain ice types (or physical properties of ice types), we rather train a neural network classifier. The neural network then implicitly encodes such relationship between parameters and ice type. Thereafter, we confirm the validity of the data clusters with in situ data. This reflects our goal of developing navigation assistance products in near real time.

Guided by these considerations, this study is structured into the following parts: We will first propose our dataset and the polarimetric parameters. After the formal introduction, the information theoretic analysis of the parameters will follow. The statistical tools of this analysis will be a rather common feature selection filter, namely the concept of mutual information (cf., [36]). Based on this statistical measure, one is able to quantify the redundancy and relevance of features for our purposes of identifying different ice types. In the third step, we present the output of our subsequent neural network classification. Since we utilize an openly accessible neural network library (FANN, see [37]), the reader is referred to the standard literature on the details of neural networks for theoretical details or for exemplary approaches in SAR-based neural network classification of sea ice (see [18] and [20]).

\section{DATASETS}

When one ultimately strives to arrive at ice charts for maritime users, the largest footprint for the desired polarimetric mode (dual-polarimetric $\mathrm{HH}-\mathrm{VV}$ in our case) is naturally the imaging mode of choice. For the readers' convenience, we provide some technical information in Table I regarding characteristics of different TSX imaging modes. The dataset used for developing this methodology have azimuth resolution of $6.6 \mathrm{~m}$ and slant range resolution of $\sim 1.2 \mathrm{~m}$. In ground range projection, the resulting StripMap dualpol image stretches about 18000 pixels in azimuth and about 6500 pixels in range direction, covering approximately $50 \mathrm{~km} \times 15 \mathrm{~km}$.

The exemplary dataset we use is a time series acquired in spring 2015 during a field campaign north of Svalbard. The image dates and locations are listed in Table II. The imaging mode for all images was StripMap Dualpol HH-VV with an incidence angle above $36^{\circ}$ for all four images as manifestations of different sea ice types are more prominent in higher incidence angles (see Table II).

For comparing our results to the actual sea ice conditions in the study area, we used in situ data collected by scientists participating in the research project Norwegian young sea ICE cruise (N-ICE2015), led by the Norwegian Polar Institute (NPI) (see [38]). In this project, the research vessel RV Lance was frozen into the sea ice in the Arctic Ocean north of Svalbard between January and June 2015, providing interdisciplinary observations from winter conditions and until the transition to early summer with the onset of melt. After the vessel had been maneuvered into the ice, it served as a drifting station and floated with the ice 
TABLE II

LIST OF TERRASAR-X DUAL-POLARIMETRIC STRIPMAP ACQUISITIONS

\begin{tabular}{lcccc}
\hline \hline Time UTC & Beam mode & Incid. ang. & Center loc. & Heading ang.(Orb Direction) \\
\hline February 07, 2015, 14:43:12 & stripNear_012 & $40-41^{\circ}$ & $82.8 \mathrm{~N}, 17.6 \mathrm{E}$ & $32.7^{\circ}$ (Ascending) \\
February 12, 2015, 14:51:37 & stripNear_012 & $40-41^{\circ}$ & $82.0 \mathrm{~N}, 19.0 \mathrm{E}$ & $33.1^{\circ}$ (Ascending) \\
February 18, 2015, 14:42:58 & stripNear_010 & $36-37^{\circ}$ & $81.8 \mathrm{~N}, 18.6 \mathrm{E}$ & $32.8^{\circ}$ (Ascending) \\
February 25, 2015, 06:26:15 & stripFar_011 & $39-40^{\circ}$ & $83.2 \mathrm{~N}, 28.8 \mathrm{E}$ & $21.4^{\circ}$ (Descending) \\
\hline \hline
\end{tabular}
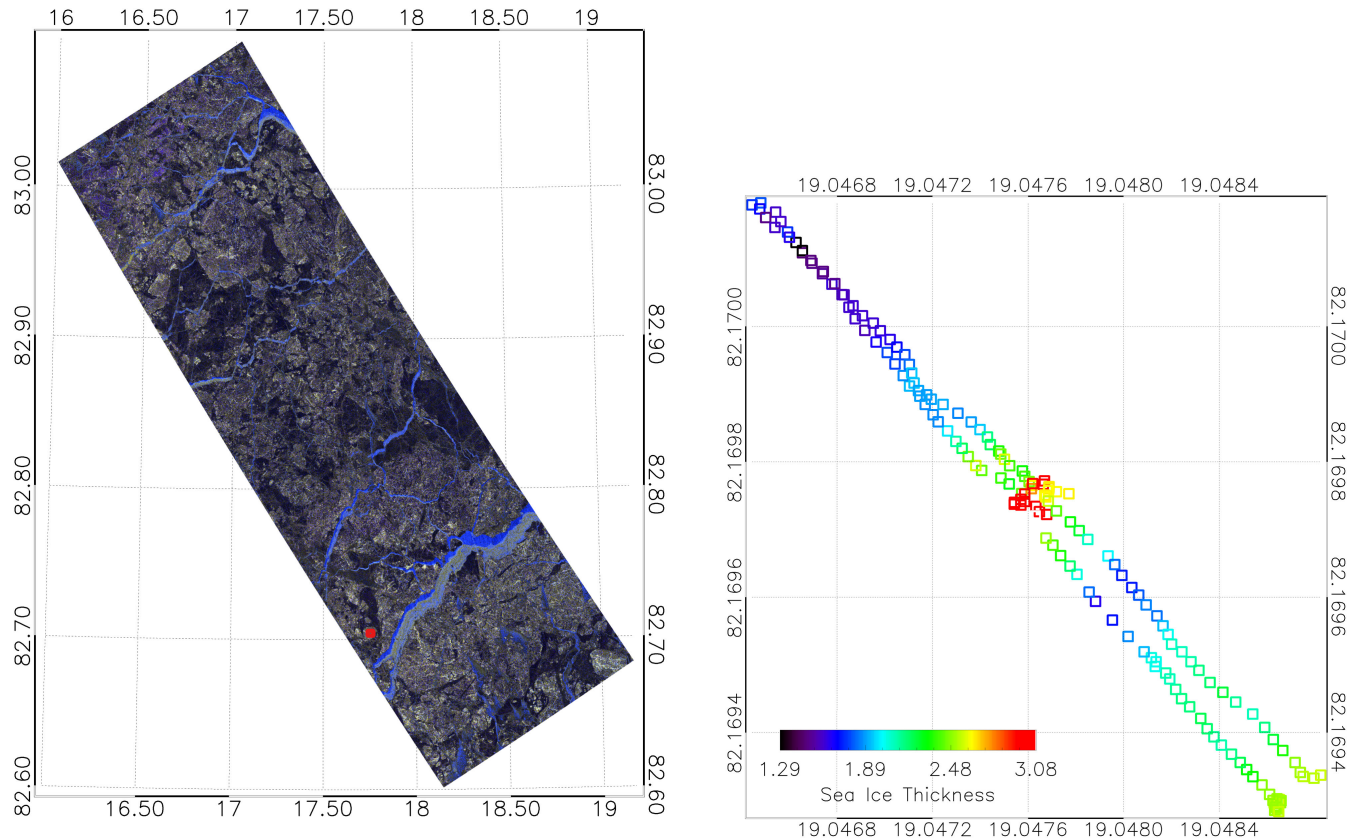

Fig. 1. Left: Geocoded RGB composite of the dual-polarimetric TS-X acquisition on February 07, 2015, with marked location of EM measurement. Right: EM measurement of ice thickness of February 11, 2015. Images depict same mooring point on different dates (i.e., differing lat,lon values are due to drift of floes).

TABLE III

POSITIONS OF THE LANCE AT INSTANCE OF ACQUISITION

\begin{tabular}{cc}
\hline \hline Date of acquisition & Position \\
\hline February 07, 2015 & $82^{\circ} 42.055862 \mathrm{~N}, 17^{\circ} 47.467877 \mathrm{E}$ \\
February 12, 2015 & $82^{\circ} 5.674461 \mathrm{~N}, 19^{\circ} 18.566928 \mathrm{E}$ \\
February 18, 2015 & $81^{\circ} 44.794054 \mathrm{~N}, 17^{\circ} 55.809365 \mathrm{E}$ \\
February 25, 2015 & $82^{\circ} 59.111275 \mathrm{~N}, 27^{\circ} 7.626262 \mathrm{E}$ \\
\hline \hline
\end{tabular}

south westwards. Once the ship reached the ice margin, it was relocated to a position further north and a new drift started. The study area of this expedition is located between $80^{\circ} \mathrm{N}-83^{\circ} \mathrm{N}$ and $3^{\circ} \mathrm{E}-28^{\circ} \mathrm{E}$ [38]. Three out of our four TerraSAR-X scenes are covering the ships position and the investigated sea ice area (see positions in Tables III.).

From this cruise, we obtained total ice thickness (ice+snow) information from ground based electromagnetic instruments (EM31), thickness drillings, and ice core data like salinity profiles to classify the ice types. For example, for February 06, 2015, the mean ice thickness of the floes next to RV Lance according to EM31 data was $2.21 \mathrm{~m}$, for February 11, 2015, the reported mean ice thickness was $2.17 \mathrm{~m}$. From these measurements, we can confirm, that three dominant ice classes, namely young ice (YI, 10-30 cm) thin to medium first-year (MFYI, 30$120 \mathrm{~cm}$ ) ice and a mixture of rough first-year and multiyear ice (RFYMYI, $>120 \mathrm{~cm}$ ) (see [39]), could be measured in the field (see example in Fig. 1). The histogram of ice thicknesses (see Fig. 3) corroborates the ice regime with open water (OW) and three different ice classes by exhibiting three major peaks in the histogram. Additionally, field researchers could confirm from visual observations that the area around the ship was mainly a composite of multiyear ice (MYI) and leveled first-year ice (FYI), broken by leads that transformed to flat new ice areas within only a few days due to cold air temperatures. As training dataset we chose the first day of the time series (February 07, 2015), which we term the training image. Training data rectangles in the image were determined close to the mooring position of the ship on February 07, 2015, relying on mentioned in situ data and ice observations (see, e.g., for two classes in the embedded zoom subimage in Fig. 2, acquired on February 12, 2015 over the floe where the ship was moored February 15, 2015 through February 21, 2015). Due to all the mentioned observations and measurements, we therefore used as the dominant ice types OW, YI, thin to MFY ice and a mixture of RFYMYI.

Given that the ice situation is similar and the incidence angle range is comparable in all images, these constraints limit 


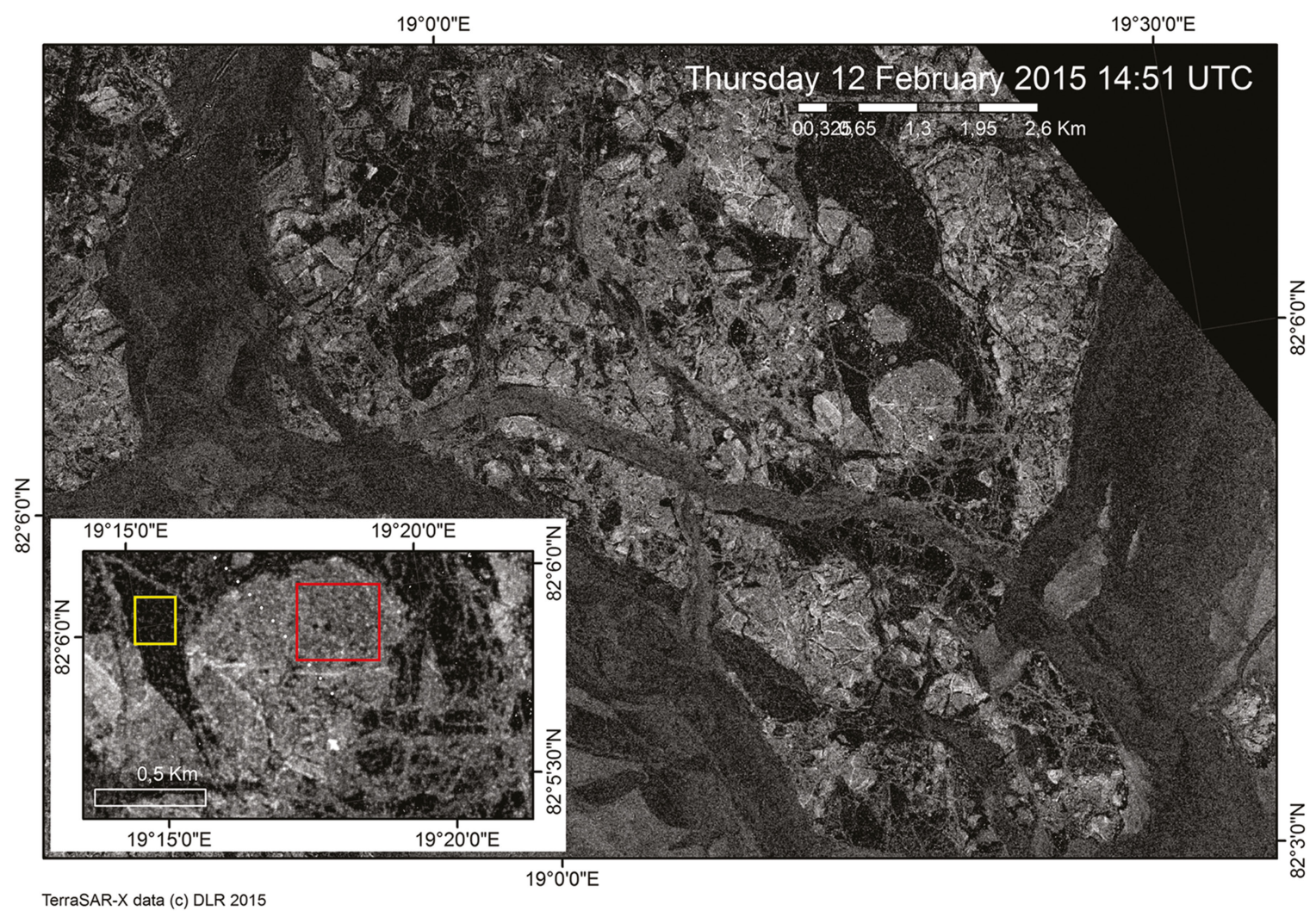

Fig. 2. Subsection of the acquisition on February 12, 2015, HH Stripmap image. Red rectangle indicates training area of RFMYI, yellow rectangle indicates training area of MFYI, other training areas not included in inlet image. The floe RV Lance was moored to can be seen in the zoom inlay. The big white dot is Lance, the small dots mark the hourly ship track. Image created by Max König of NPI, Norway.

the variability of backscatter behavior in dominant ice types. In operational situations, one will aspire to have a classifier for each (narrow) incidence angle range to account for this. Named variability normally makes a supervised classification approach rather difficult (cf., [33] and [34]) and necessitates to establish a library of classifiers, each for reasonably homogeneous acquisition conditions such as weather, season, and incidence angle. An issue to mind is weather events such as melting and refreezing that are known to alter the scattering mechanism significantly (cf., [40]). In our case, the weather data, collected in situ during the N-ICE2015 campaign, are well within winter conditions (polar night) with no thaw at all. For these reasons, we do not expect a strong variation in the dominant ice types, nor in the backscatter behavior due to weather impact. Frost flowers on refrozen leads were observed rather frequently by cruise members, which needs to be kept in mind when discussing the SAR backscatter and the classification output.

\section{POLARIMETRIC FEATURES}

For spaceborne SAR data of C-band and L-band, the behavior of polarimetric features for different ice types has been investigated before (e.g., [27], [33], [34], [41], and [42]). Studies that compare X-band, C-band, and L-band in sea ice research data are, for example, [28] or in [43]. Given that C-band is rather close to X-band SAR, we expect to find a similar behavior in our data (cf., [43]). Before we discuss the expected behavior in C-band and L-band, we propose our dual-polarimetric defini- tion for the features. By $S_{\mathrm{HH}}$ we denote the complex backscatter return as obtain in the delivered TerraSAR-X product. $\sigma_{\mathrm{HH}}$ denotes the amplitude of $S_{\mathrm{HH}}$ and $\phi_{\mathrm{HH}}$ denotes the phase angle of $S_{\mathrm{HH}}$, i.e.,

$$
S_{\mathrm{HH}}=\sigma_{\mathrm{HH}} \exp \left(i \phi_{\mathrm{HH}}\right) .
$$

Likewise notation is used for $S_{\mathrm{Vv}}$. The brackets $\langle\cdot\rangle$ denote the local averaging process during polarimetric feature extraction. (The spatial averaging window size was chosen to be 11 pixels for our sample dataset throughout this publication.) The complex signal vectors in lexicographic basis representation and Pauli basis representation are then

$$
k_{L}=\left(S_{\mathrm{HH}}, S_{\mathrm{VV}}\right), k_{P}=\frac{\left(S_{\mathrm{HH}}+S_{\mathrm{VV}}, S_{\mathrm{HH}}-S_{\mathrm{VV}}\right)}{\sqrt{2}} .
$$

In a polarimetric approach, one generally first computes the (locally averaged) covariance matrix of the scattering vector (e.g., in Pauli or lexicographic basis)

$$
T_{P}=\left\langle k_{P}^{t r} \cdot k_{P}\right\rangle
$$

and

$$
T_{L}=\left\langle k_{L}^{t r} \cdot k_{L}\right\rangle .
$$

The particular parameters are inspired by the ones outlined in [29], [35], and [44].

The eigenvalues $\lambda_{1}$ and $\lambda_{2}$ of $T_{P}$ are used to compute the scattering probabilities $p_{j}=\lambda_{j} /\left(\lambda_{1}+\lambda_{2}\right)$. This is the input for 


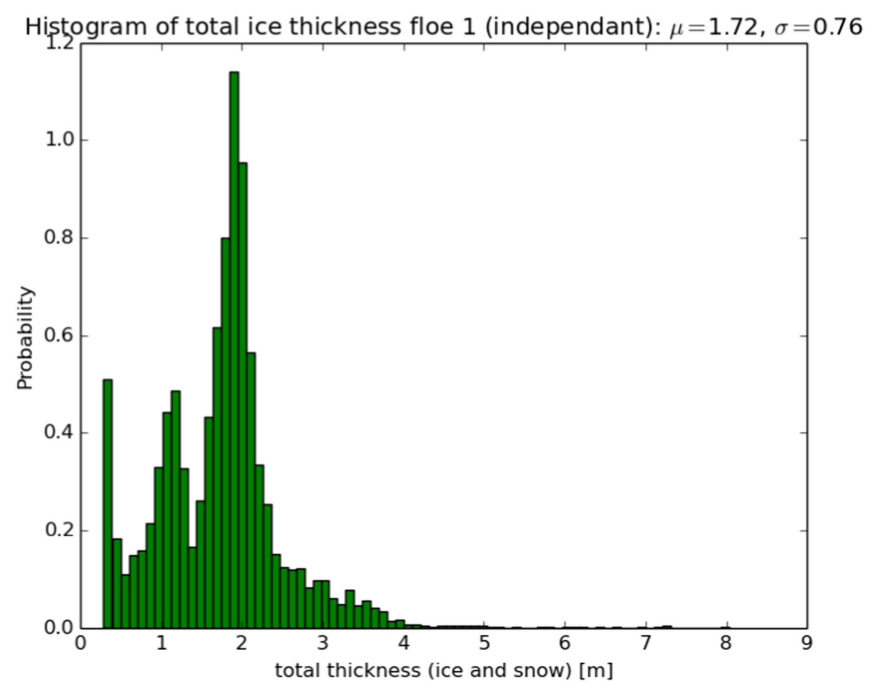

Fig. 3. Histogram of ice thickness values measured on the floe, which RV Lance was moored to January 15, 2015-February 21, 2015. Three peaks indicate the three dominant ice types (YI $(10-30 \mathrm{~cm})$, MFYI $(30-120 \mathrm{~cm})$, RFYMYI $>120 \mathrm{~cm})$, see aforementioned definition) observed in the surrounding of the ship.

deriving entropy

$$
H=-\left(p_{1} \log _{2}\left(p_{1}\right)+p_{2} \log _{2}\left(p_{2}\right)\right)
$$

and anisotropy

$$
A=\frac{\left(p_{1}-p_{2}\right)}{\left(p_{1}+p_{2}\right)} .
$$

From the eigenvectors $v_{1}$ and $v_{2}$ of $T_{P}$, one obtains

$$
\alpha_{i}=\arccos \left(v_{j}^{(1)}\right), j=1,2 .
$$

We also compute the average $\alpha$ angle

$$
\alpha=\alpha_{1} p_{1}+\alpha_{2} p_{2} \text {. }
$$

While the classical $H / A / \alpha$ parameters (cf., [29]) in the fully polarimetric case also permit the physical interpretation (e.g., about predominant scattering mechanisms), we do not further explore this aspect for our 2-D adaptations. In any case, the Pauli-based parameters can certainly be interpreted as statistical parameters characterizing different types of sea ice surfaces.

From $T_{L}$, we derive a number of parameters, inspired by [35] and by [44], which are as follows.

Copolarization power ratio

$$
\gamma=\frac{\left\langle\left|S_{\mathrm{HH}}\right|^{2}\right\rangle}{\left\langle\left|S_{\mathrm{VV}}\right|^{2}\right\rangle}
$$

Phase difference

$$
\Delta \phi=\phi_{\mathrm{HH}}-\phi_{\mathrm{VV}} .
$$

Real part of the copolarization cross product

$$
\rho=\left|\Re\left\langle S_{\mathrm{HH}} S_{\mathrm{VV}}^{*}\right\rangle\right| \text {. }
$$

Correlation

$$
\varepsilon=\frac{\left\langle S_{\mathrm{HH}} S_{\mathrm{VV}}^{*}\right\rangle}{\sqrt{\left\langle\left|S_{\mathrm{HH}}\right|^{2}\right\rangle\left\langle\left|S_{\mathrm{VV}}\right|^{2}\right\rangle}} .
$$

Span of $T_{L}$

$$
\operatorname{span}=\operatorname{trace}\left(T_{L}\right) .
$$

Scattering diversity (where $\|\cdot\|_{F}$ denotes the matrix Frobenius norm)

$$
\delta=2\left(1-\left(\frac{\left\|T_{L}\right\|_{F}}{\operatorname{span}}\right)^{2}\right) .
$$

Surface scattering fraction

$$
\tau=\frac{\left\langle\left|S_{\mathrm{HH}}+S_{\mathrm{VV}}\right|^{2}\right\rangle}{\operatorname{span}} .
$$

Geometric Intensity $\mu$

$$
\mu=\left(\operatorname{det}\left(T_{L}\right)\right)^{(1 / 2)} .
$$

The C-band copol power ratio is known to provide an excellent measure to distinguish OW and all other ice types, in particular very thick ice types (see [41] or [27]). For the younger ice type, the reported copol power ratio is closer to the respective values of OW. The C-band phase difference $\Delta \phi$ is reported to be useful for discriminating different thinner ice types (see [27], [33], and[42]). For L-band, (quad-polarimetric) entropy $H$ is known to distinguish OW from ice types generally well and also thin ice from thick ice types due to the underlying different scattering mechanisms(see [28]). (Quad-polarimetric) L-band anisotropy is known to be sensitive to surface roughness (see [28]), although in our case, the anisotropy is calculated differently, and thus, cannot be assumed to have the same physical meaning. In fact, we will show further that (dual polarimetric) $A$ is for mathematical reasons more closely related to $H$.

\section{Mutual Information, RELEVANCE AND REDUNDANCY OF FEATURES}

To quantify the behavior of the different ice types we have collocated the histograms for the mentioned features by class (see Fig. 4). From the histograms, one can already gather quite well which features distinguish certain classes quite distinctively and which are not very discriminative in terms of class.

To quantify this in a more rigorous way, we employ an information-theoretic idea, which has become a rather central tool in analyzing informational content and discrimative power, namely mutual information.

The concept of mutual information has become a rather popular tool in the field of feature selection for machine learning (cf., [36] and [45]). In our case, we are not confronted with a huge number of features. As hinted in the introduction, in our case, the major challenge lies in the size of full resolution data take: In the case of TerraSAR-X one full-resolution purely real-valued image layer occupies about $600 \mathrm{MB}$ of RAM, in case of Sentinel dual-polarimetric data, this can be as much as 4 GB for one real-valued layer of a dual-polarimetric image. Multiplying this memory consumption by the number of (realvalued) polarimetric features, one clearly sees the advantage of analyzing the relevance and redundancy of features first and retaining only those features necessary for a reasonably accurate classification. 


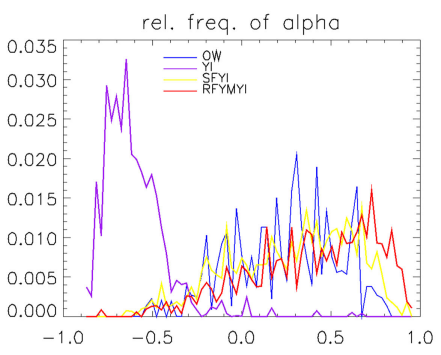

(a) $\alpha$

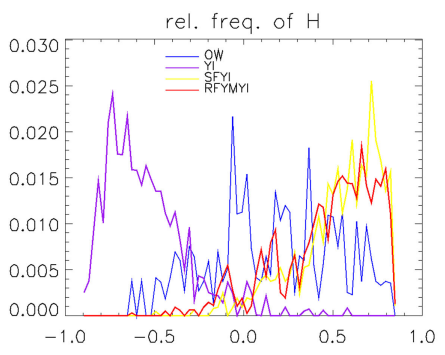

(d) $\mathrm{H}$

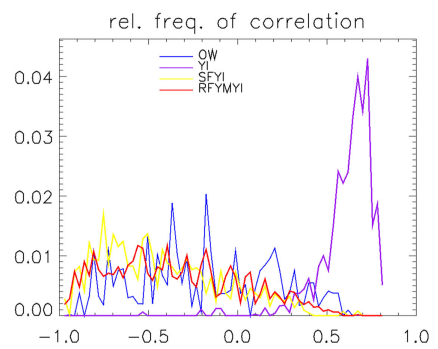

(g) $\varepsilon$

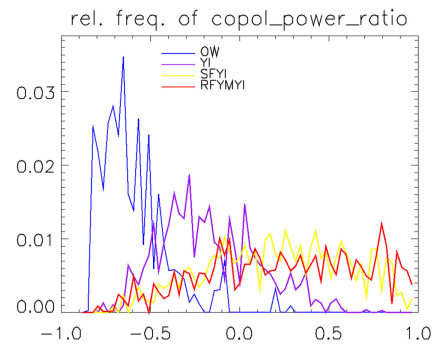

(j) $\gamma$

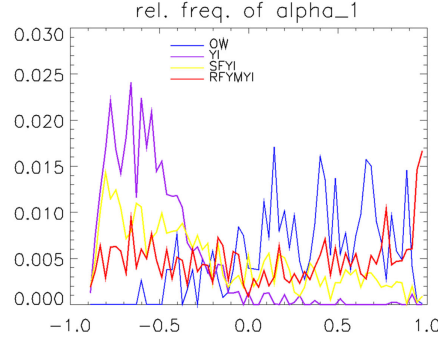

(b) $\alpha_{1}$

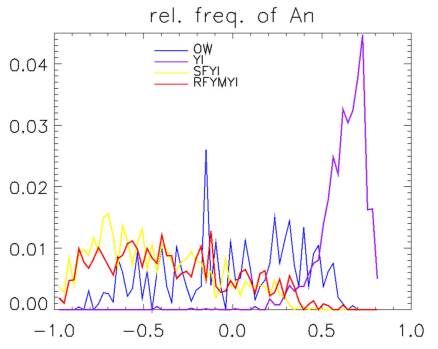

(e) $\mathrm{A}$

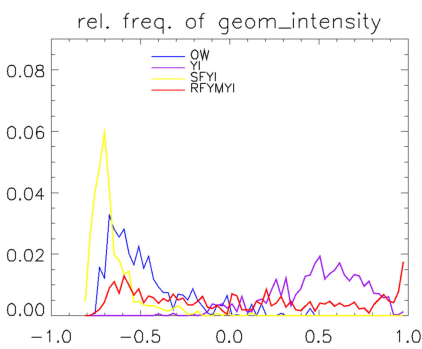

(h) $\mu$

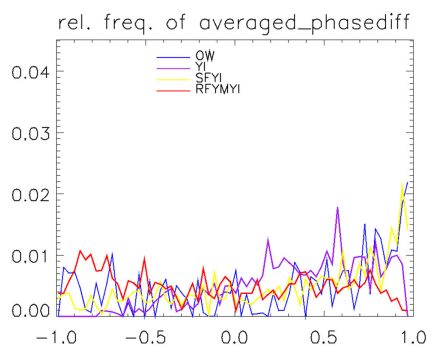

(k) $\Delta \varphi$

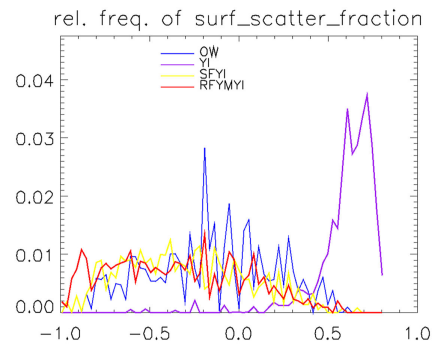

(c) $\tau$

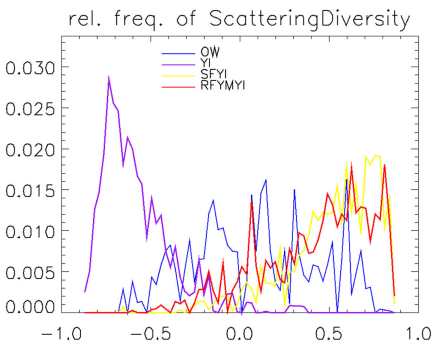

(f) $\delta$

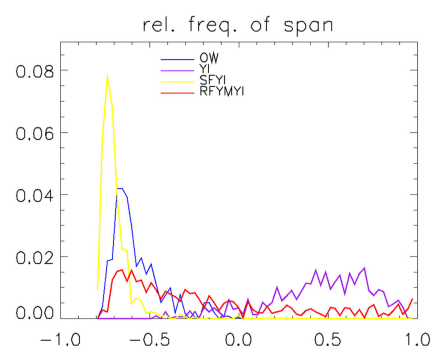

(i) $\operatorname{span}$

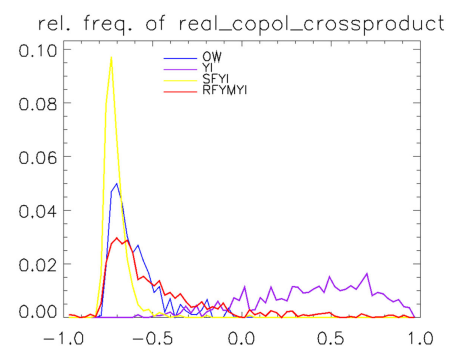

(1) $\rho$

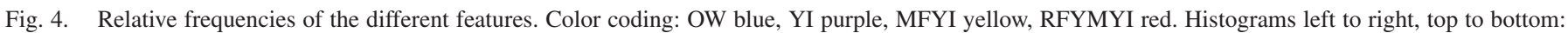
angle $\alpha$, angle $\alpha_{1}$, surface scatter fraction $\tau$, entropy $H$, anisotropy $A$, scattering diversity $\delta$, correlation, geometric intensity $\mu$, span, copol power ratio $\gamma$, averaged phase difference $\Delta \varphi$, and real copol cross product $\rho$.

\section{A. Mutual Information for Feature Selection}

Given two random variables $X$ and $Y$ (with joint and marginal densities, no point masses), the mutual information $\mathcal{I}$ of these variables is defined as

$$
\mathcal{I}(X \mid Y)=\mathcal{H}(X)-\mathcal{H}(X \mid Y)
$$

where $\mathcal{H}(\mathcal{X})$ denotes the entropy and $\mathcal{H}(X \mid Y)$ denotes the conditional entropy of $X$ given $Y$. For details, confer [36] and [45]. Intuitively, $\mathcal{I}$ can be said to describe the portion of information that is shared by both, $X$ and $Y$, i.e., their "information overlap." Put differently, the higher $\mathcal{I}(X \mid Y)$, the more information one can infer about $X$ from existing knowledge of $Y$. In this way, one can measure, in an information theoretical sense, the (nonlinear) information correlation of $X$ and $Y$. The symmetry of $\mathcal{I}$ in $X$ and $Y$, which one would expect for the intuitive concept of "shared information," also holds for the strict mathematical definition, i.e., $\mathcal{I}(X \mid Y)=\mathcal{I}(Y \mid X)$. Given $\mathcal{I}$ is a dimensionless quantity, we use it only as a means to put different features in comparison. The absolute value of $\mathcal{I}$ we do not investigate further here.

As an example (we do not use here), one could let $X$ be the backscatter brightness, $Y_{1}$ be the ice roughness, and $Y_{2}$ ice thickness. Surface roughness generally corresponds to higher 
backscatter, whereas backscatter and ice thickness have no simple general functional relationship (but volume scattering may be indicative of thick ice). So, for this hypothetical setup, $\mathcal{I}\left(X \mid Y_{1}\right)>>\mathcal{I}\left(X \mid Y_{2}\right)$.

We introduce the following terminology concerning particular choices of $X$ and $Y$ : In case, $Y$ is a feature and $X$ is the class information ( $X$ attains, e.g., OW, YI, MFYI, and RFYMYI), a (relatively) high mutual information $\mathcal{I}$ would indicate a high predictive value of feature $Y$ for determining the class $X$. Or symmetrically, knowledge of the class $X$ allows reliable prediction of pertaining values of $Y$. If $X$ is chosen to only attain two classes (i.e., we only utilize training data from two classes to determine $\mathcal{I}(X \mid Y)$ ), the mutual information value then indicates the particular discriminative power of the feature $Y$ for distinguishing those two particular classes. This configuration $(Y$ feature, $X$ all classes or two classes $a$ and $b$ ) we use to rank the features according to relevance (all-class relevance, two-class relevance). We will write $\mathcal{I}(Y \mid \operatorname{Class}($ all $))$ or $\mathcal{I}(Y \mid \operatorname{Class}(a, b))$ for these situations.

In another setup, we let $X$ and $Y$ be two different features. When $\mathcal{I}(X \mid$ Class(all $))$ and $\mathcal{I}(Y \mid$ Class(all) $)$ are about equal (i.e., have equal relevance), high mutual information $\mathcal{I}(X \mid Y)$ then is said to indicate redundancy. Such redundancy we will find in our sample data and we will use it to justify discarding some features. To obtain a higher comparability, $\mathcal{I}(X \mid Y)$ is normalized by $\sqrt{\mathcal{H}(X)}$.

Since we input the features into a neural network classifier, all features are rescaled into the range $[-1.0,1.0]$. This way the feature values lie in the range where the sigmoidal of the neural network is not near-constant. We utilize a popular nonlinear rescaling method involving the tanh function

$$
\tilde{x}=\tanh \left(\frac{x-\bar{X}}{\nu_{X}}\right)
$$

where $\bar{X}$ denotes the mean of all values of feature $X$ in the training data and $\nu_{X}$ denotes the standard deviation of all values of feature $X$ in the training data. When a neural network is trained on data rescaled with these particular training data statistical parameters $\mathcal{P}=\left\{\bar{X}, \nu_{X}\right\}$, then all feature vectors that are afterwards ingested into this network for classification must be rescaled with these parameters $\mathcal{P}$ prior to classification. In all further analysis, we only consider the rescaled values of the feature, since they determine the behavior of the classifier.

From first glance at Table IV, entropy $H$, anisotropy $A$, and scattering diversity $\delta$ rank in the same order of relevance. Furthermore, the angle $\alpha$ and $\alpha_{1}$ are found to be not very relevant.

As can be seen in Table $\mathrm{V}$, for discriminating OW from the thick ice classes (MFYI, RFYMYI), the copolarization power ratio $\gamma$ is the most relevant feature. This is a well-known fact and demonstrated for different bands (cf., e.g.,[19] and [41]). Since this discrimination is of major importance for navigation through ice-infested waters, $\gamma$ can be considered indispensible in our classification. Another observation from Table $\mathrm{V}$ is that the triplet $\delta, H$, and $A$ almost always appear in the same place together. In fact, numerically the two-class relevances of these three features hardly differed at all (the biggest value exceeding
TABLE IV

Relevance for Distinguishing All DifFerent Classes (All Class RELEVANCE)

\begin{tabular}{lccc}
\hline \hline Feature & $\mathcal{I}_{0}$ & $\mathcal{I}_{1}$ & Reference Histograms \\
\hline span & 0.862 & 0.390 & $4 \mathrm{i}$ \\
Geometric intensity $\mu$ & 0.849 & 0.382 & $4 \mathrm{~h}$ \\
Real part copol cross prod. $\rho$ & 0.799 & 0.363 & 41 \\
Anisotropy $A$ & 0.781 & 0.343 & $4 \mathrm{e}$ \\
Entropy $H$ & 0.779 & 0.344 & $4 \mathrm{~d}$ \\
Scattering diversity $\delta$ & 0.775 & 0.342 & $4 \mathrm{f}$ \\
surface scattering fraction $\tau$ & 0.730 & 0.32 & $4 \mathrm{c}$ \\
Correlation $\varepsilon$ & 0.717 & 0.315 & $4 \mathrm{~g}$ \\
Copol power ratio $\gamma$ & 0.686 & 0.300 & $4 \mathrm{j}$ \\
average angle $\alpha$ & 0.661 & 0.289 & $4 \mathrm{a}$ \\
angle $\alpha_{1}$ & 0.394 & 0.173 & $4 \mathrm{~b}$ \\
Averaged phase difference $\Delta \phi$ & 0.195 & 0.085 & $4 \mathrm{k}$ \\
\hline \hline
\end{tabular}

$\mathcal{I}_{0}$ denotes $\mathcal{I}(X \mid \operatorname{Class}($ all $))$ and $\mathcal{I}_{1} \operatorname{denotes} \mathcal{I}(X \mid \operatorname{Class}($ all $)) / \sqrt{H(X)}$.

TABLE V

Two-Class ReleVAnCe in Descending ORDER FOR DiFFERENT PAIRS OF Classes

\begin{tabular}{lccccc}
\hline \hline 1 Versus 2 & 1 Versus 3 & 1 Versus 4 & 2 Versus 3 & 2 Versus 4 & 3 Versus 4 \\
\hline$\rho$ & $\gamma$ & $\gamma$ & span & $\tau$ & $\mu$ \\
span & $A$ & $A$ & $\rho$ & $H$ & span \\
$\mu$ & $\delta$ & $H$ & $\mu$ & $\delta$ & $\rho$ \\
$\alpha$ & $H$ & $\delta$ & $\delta$ & $A$ & $\Delta \phi$ \\
$\tau$ & $\operatorname{span}$ & $\mu$ & $H$ & $\varepsilon$ & $\alpha_{1}$ \\
$\alpha_{1}$ & $\rho$ & $\tau$ & $A$ & $\alpha$ & $\alpha$ \\
$\varepsilon$ & $\varepsilon$ & $\varepsilon$ & $\varepsilon$ & $\rho$ & $\varepsilon$ \\
$\gamma$ & $\mu$ & $\operatorname{span}$ & $\tau$ & $\operatorname{span}$ & $\tau$ \\
$H$ & $\alpha$ & $\alpha$ & $\alpha$ & $\mu$ & $A$ \\
$\delta$ & $\tau$ & $\alpha$ & $\gamma$ & $\alpha_{1}$ & $H$ \\
$A$ & $\alpha$ & $\Delta \phi$ & $\alpha_{1}$ & $\gamma$ & $\gamma$ \\
$\Delta \phi$ & $\Delta \phi$ & $\rho$ & $\Delta \phi$ & $\Delta \phi$ & $\delta$ \\
\hline \hline
\end{tabular}

Class indices are: 1: OW, 2: YI, 3: MFYI, 4: RFYMYI

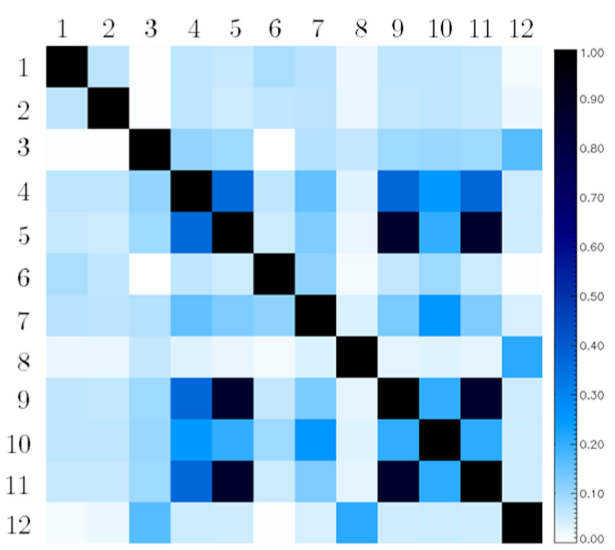

Fig. 5. Normalized mutual information $\mathcal{I}\left(Y_{1}, Y_{2}\right) / \sqrt{\mathcal{H}\left(Y_{1}\right) \mathcal{H}\left(Y_{2}\right)}$. Features are: $1: \gamma, 2: \Delta \phi, 3: \rho, 4: \varepsilon, 5: H, 6: \alpha_{1}, 7: \alpha, 8: \mu, 9: A, 10: \tau, 11: \delta, 12:$ span.

the smallest by at most 3\%) for all but the case MFYI versus RFYMYI (where the biggest value exceeds the smallest by less than $10 \%)$.

The (normalized) mutual information for our particular dataset is displayed in Fig. 5. Since we are only interested in relative comparison, such a color-coded matrix offers an easy 


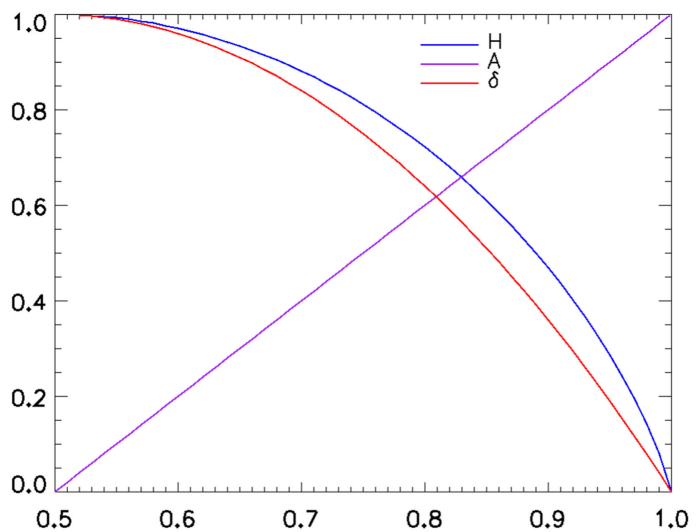

Fig. 6. Values of features $H, A$, and $\delta$ in terms of the scattering probability $p_{1}$.
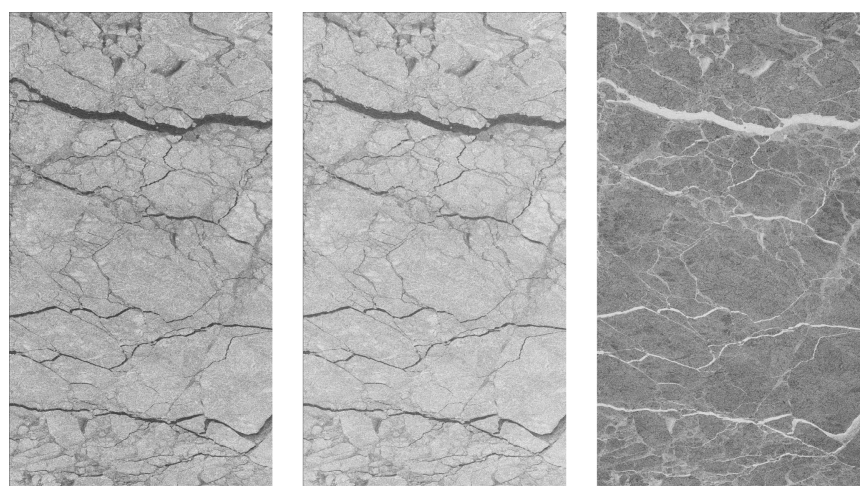

Fig. 7. Left: Scattering diversity $(\delta)$; middle: Entropy $(H)$; right: Anisotropy $(A)$ of February 07, 2015 TSX image (window size $-11 \times 11$, gray scale representation).

way to comprehensively assess redundancy of the features. The most striking observation in Fig. 5 is the high correlation of the polarimetric entropy $H$, anisotropy $A$, and the scattering diversity $\delta$, which fits quite well the theoretical predictions of [35, Sec. III-B]. This can also be observed by visual comparison of $H$ and $\delta$ in Fig. 7, and for $H$ and $A$, minding the inverted information in the gray values of $A$. The fact that $H, A$, and $\delta$ are so closely related can also be expressed mathematically in terms of the eigenvalues. Referring to (5), we have $p_{2}=1-p_{1}$, we obtain

$$
H=-p_{1} \log _{2}\left(p_{1}\right)-\left(1-p_{1}\right) \log _{2}\left(1-p_{1}\right)
$$

and likewise

$$
A=2 p_{1}-1
$$

For the scattering diversity $\delta$, a straightforward computation shows

$$
\delta=4\left(p_{1}-p_{1}^{2}\right) .
$$

Noting that $p_{1} \in[0.5,1.0]$ for mathematical reasons, one can see the close relationship between the three features directly in Fig. 6.

The formulas and Fig. 6 highlight that $\delta$ can be regarded as a second-order polynomial approximation of $H$, and $\tilde{A}=$ $1-A$ would be a linear approximation of $\delta$. So, for any dual- polarimetric SAR image, one would arrive at high visual match and mutual information for $H, \tilde{A}$, and $\delta$.

To a lesser degree, the correlation feature $\varepsilon$ also bears similar information content to $H, A$, and $\delta$. For our purposes of detecting redundancy, we do not consider any other similarities in Fig. 5.

Therefore, we can summarize the most relevant features (the top three features for each class pair) as $\gamma, \mu$, span, $\tau$, and $\rho$ by two-class relevances (see Table $\mathrm{V}$ ), discarding redundant entropy $H$ and anisotropy $A$. By all-class relevance, the five most relevant features (neglecting $A$ and $H$ ) are $\mu$, span, $\tau, \rho$, and $\delta$. Only the copol power ratio $\gamma$ appears rather off due to the fact, that it is primarily important for discriminating thick ice classes and OW but not so much for discriminating the thick ice classes or thicker ice classes and YI. This matches reported backscatter behavior for $\gamma$ in C-band (see [46]).

Combining all the findings for relevance and redundancy, we expect a reduced feature set comprising $\mu$, span, $\tau, \rho, \delta$, and $\gamma$ to lead to comparable classification results when utilizing all 12 features mentioned. This finding would greatly reduce the computational overhead in applications since mentioned six features do not rely on an eigendecomposition of the coherency matrix. We finally remark that the mutual-information-based analysis we conducted for individual features can be generalized to higher orders, i.e., consider combinations of features as one feature and compute relevance and redundancy. For this study, we do not pursue such an analysis further but remark, that future work will explore this aspect.

\section{Classification Results}

As mentioned in the introduction, we performed a supervised classification using an artificial neural network (ANN). The parameter subset we used was $\mathcal{S}$, which included $(\mu$, span, $\gamma, \rho, \delta$, and $\tau$ ) plus their respective local variances.

The implementation was carried out in the Exelis IDL programming language (Image ingestion, incidence angle correction, feature extraction, and statistical analysis) and in C (FANN library classifier). The network topology we used had three hidden layers of 14, 16, and 7 hidden neurons per layer, respectively. The training algorithm was resilient backpropagation (RPROP), with randomly initiated weights. The computation time for the extraction ranged at about $400 \mathrm{~s}$ for the feature extraction. The classification runtime depends on the size of the output, where a classification and execution on the full resolution took about $1000 \mathrm{~s}$ (hardware: 11-GB RAM, Intel Core i-7 3740 QM). Therefore, this approach is clearly suitable for near real-time delivery to maritime end users, in particular, for ice routing in the ice-infested waters. To see whether the training process (with random starting weights in the ANN) is stable for different choices of training data (from February 07, 2015), we randomly split the initial patches of identified ice types (with known reference ice class) into two disjoint subsets $\left(U_{1}, U_{2}\right)$. The subset $U_{1}$ we use as training data and the trained classifier from this training dataset is then executed on the nontraining dataset $U_{2}$. We repeat this procedure ten times (with random initial weights of the ANN) with roles of $U_{1}$ and $U_{2}$ reversed 

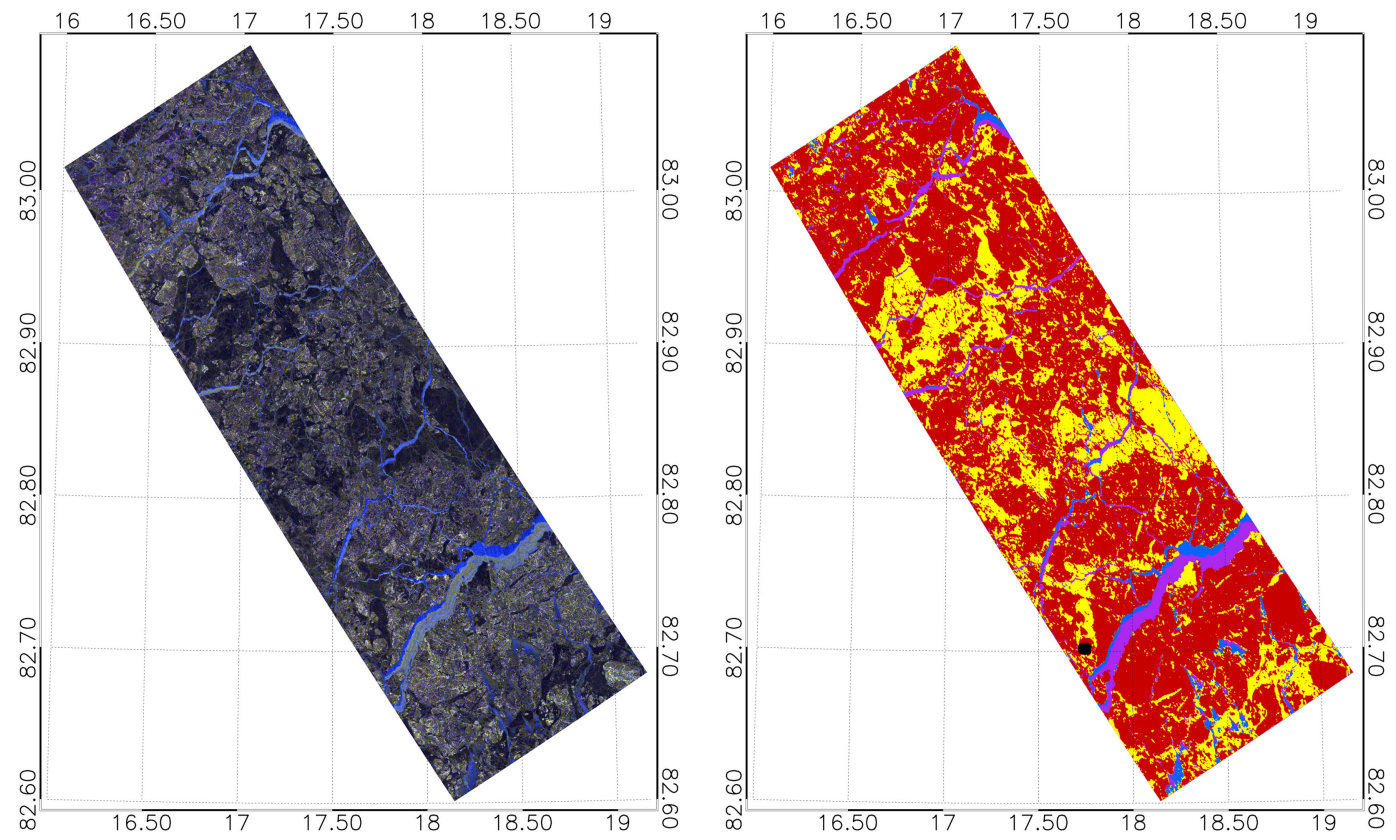

Fig. 8. Left: Geocoded RGB composite of the dual-polarimetric TSX acquisition on February 07, 2015. Right: Ice classification based on copol power ratio $\gamma$, geometric intensity $\mu$, scattering diversity $\delta$, surface scattering fraction $\tau$, span, real copol cross product $\rho$. and local variances for each feature. Blue: OW/nilas, purple: YI, yellow: first-year ice (MFYI), red: rough first-year ice/multiyear ice (RFYMYI). Black dot marks position of RV Lance.

TABLE VI

Classification Results COMPARED to REFERENCE Data SAMPLES From

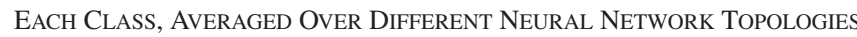

\begin{tabular}{lcccc}
\hline \hline & \multicolumn{4}{c}{ Reference Ice Class } \\
\hline ANN Classification & OW & YI & MFYI & RFYMYI \\
OW & $99.0 \%$ & $13.5 \%$ & $0 \%$ & $0 \%$ \\
YI & $1.0 \%$ & $86.5 \%$ & $0 \%$ & $0 \%$ \\
MFYI & $0 \%$ & $0 \%$ & $100 \%$ & $1.9 \%$ \\
RFYMYI & $0 \%$ & $0 \%$ & $0 \%$ & $98.1 \%$ \\
\hline \hline
\end{tabular}

for training and nontraining subsets. For each execution of the classifier on the nontraining dataset, we compute the percentage of output into the different ice classes, recording also the reference ice class of the respective input pixel. This classification output we interpret as an indicator of stability of the classification procedure (not to be confused with validation, i.e., testing of classifiers on portions of images of February 12, 2015 or later dates). The percentages in the matrix (see Table VI) indicate the proportion of samples of one reference class that were assigned to the respective ice type by the classifiers. Therefore, columns add up to $100 \%$. Given that both training and validation data are from the same ice situation (i.e., same time, location, and incidence angle), we can conclude quantitatively that our approach is consistent in itself and is stable in terms of the choice of the training data.

Classification results for all four TSX images are presented in Figs. 8-11. Since for the first two dates, the RV Lance was moored at the same ice floe, we discuss these two dates together. For the last date (February 07, 2015), we will also discuss the result with regards to in situ observations. For the third date of the series, the readers have to content themselves with visually judging the plausibility of the result by taking the Pauli image and the preceding classification results into account, as no in situ data are available for that date.

Salinity measurements at the first moored point next to Lance marked in the scenes of February 7 and 12 (see Figs. 8 and 9) confirm by the low salinity in the upper part of the floe that the ice is correctly classified as RFYMYI. The ice floe had low salinity, which indicates that the floe had survived at least one summer melt. To see the consistency of the classification from February 07, 2015 to the next date (February 12, 2015) consider the magnified subsections of the floe where the Lance was mooring (left and center image in Fig. 12).

Also the MFYI to the north and north-east of the mooring floe is identified correctly. The in situ measurements clearly show a thinner, more saline ice for these regions. The refrozen leads toward the south of the mooring position in the acquisition of February 12, 2015 (see center image in Fig. 12) were, however, mostly classified as RFYMYI even though the Pauli image suggests YI. This is due to the classification procedure itself, since the kind of YI, which appears with a purple hue on February 12, 2015 does not yet appear in the image of February 07, 2015. For this technical reason, the classifier is not trained on this variant of YI and incorrectly classifies these YI portions as RFYMYI.

The floe next to Lance on February 25, 2015 (see Figs. 11 and 12) actually was a composite of two floes: MYI toward the East and FYI toward to the West as salinity and thickness measurements show. They are both classified as RFYMYI. The FYI part was smoother than the MYI part. The FYI part, however, also showed signs of deformation. We, therefore, consider the classification successful. The FYI part of the floe next to RV Lance was thicker than the thin FYI toward the North-West and South. This thinner FYI ice is correctly classified as MFYI (yellow) 

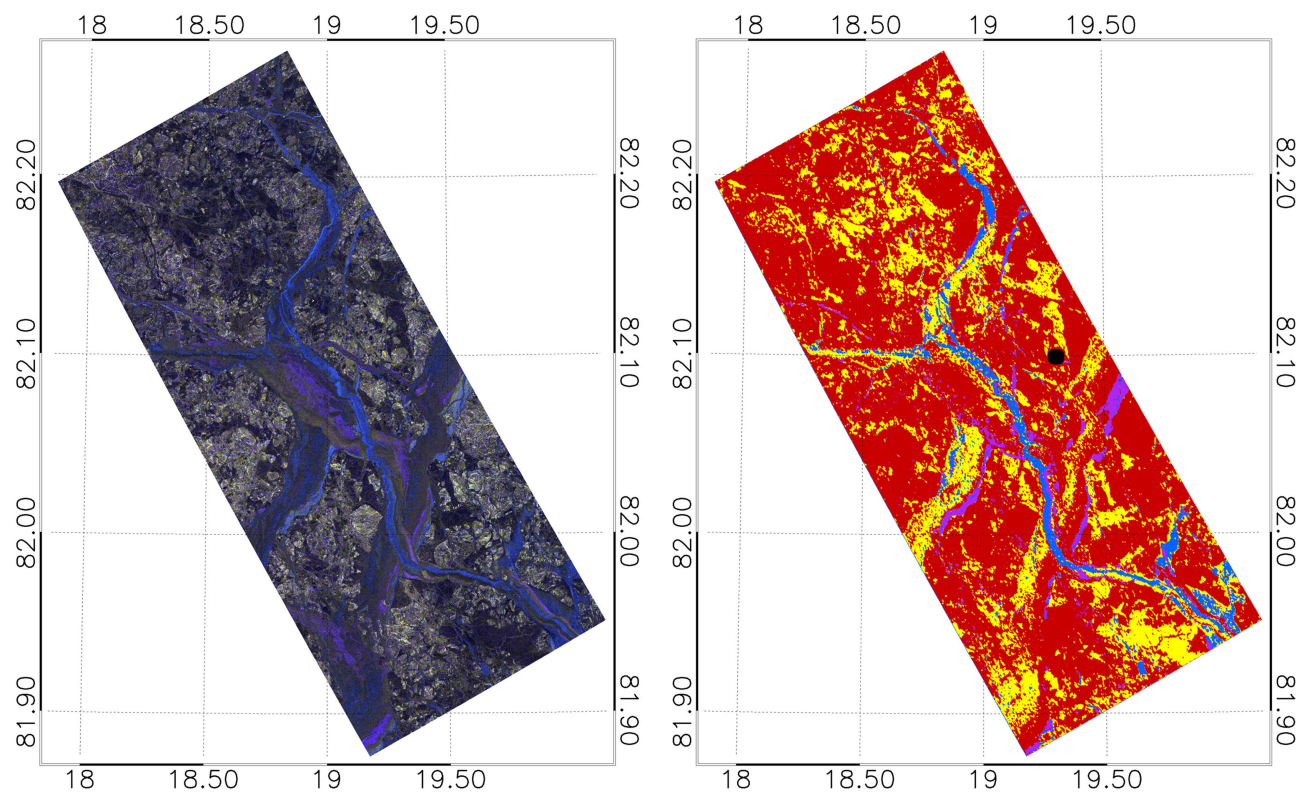

Fig. 9. Left: Geocoded RGB composite of the dual-polarimetric TSX acquisition on February 12, 2015. Right: Ice classification based on copol power ratio $\gamma$, geometric intensity $\mu$, scattering diversity $\delta$, surface scattering fraction $\tau$, span span, and real copol cross product $\rho$, and local variances for each feature. Blue: OW/nilas, purple: YI, yellow: first-year ice (MFYI), red: rough first-year ice/multiyear ice (RFYMYI). Black dot marks position of RV Lance.
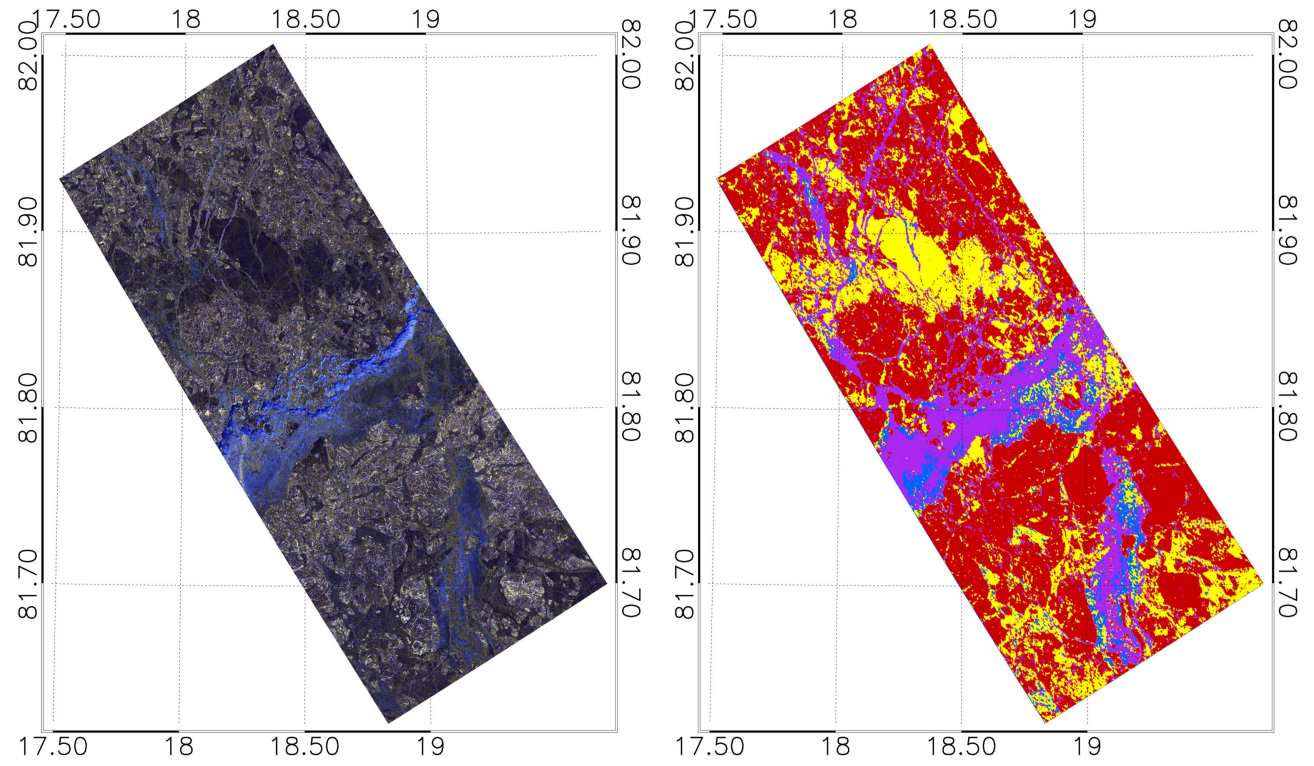

Fig. 10. Left: Geocoded RGB composite of the dual-polarimetric TSX acquisition on February 18, 2015. Right: Ice classification based on copol power ratio $\gamma$, geometric intensity $\mu$, scattering diversity $\delta$, surface scattering fraction $\tau$, span span, real copol cross product $\rho$, and local variances for each feature. Blue: OW/nilas, purple: YI, yellow: first-year ice (MFYI), red: rough first-year ice/multiyear ice (RFYMYI). Black dot marks position of RV Lance.

by our method. By the visual observations from aboard the ship one would not necessarily call it smooth. It actually showed a significant number of small ridges with level ice in-between. A possible alternative labeling for our ice type classes therefore also could be: thin to medium first-year ice (MFYI, 30-120 cm according to WMO [39]) and thick FYI $(>120 \mathrm{~cm})$. The YI in the lead toward the South-East is correctly identified. It was still OW when RV Lance arrived about $24 \mathrm{~h}$ before and had an approximate thickness of $10-15 \mathrm{~cm}$ when the TerraSAR-X image was acquired. In summary, the in situ observations confirm the automatic classification and can attest a high agreement.
There is only a limited amount of in situ observations available, and therefore, only a small fraction of the classified ice could be evaluated. One, however, has to keep in mind that this is one of the rare occasions that high quality winter time in situ data is available at all, and to our knowledge, the first time that SAR classification results could be evaluated (in this part of the Arctic) under no-light conditions.

\section{CONCLUSION}

Until recently sea ice classification using X-band SAR was rather uncharted research domain. We investigated the potential 

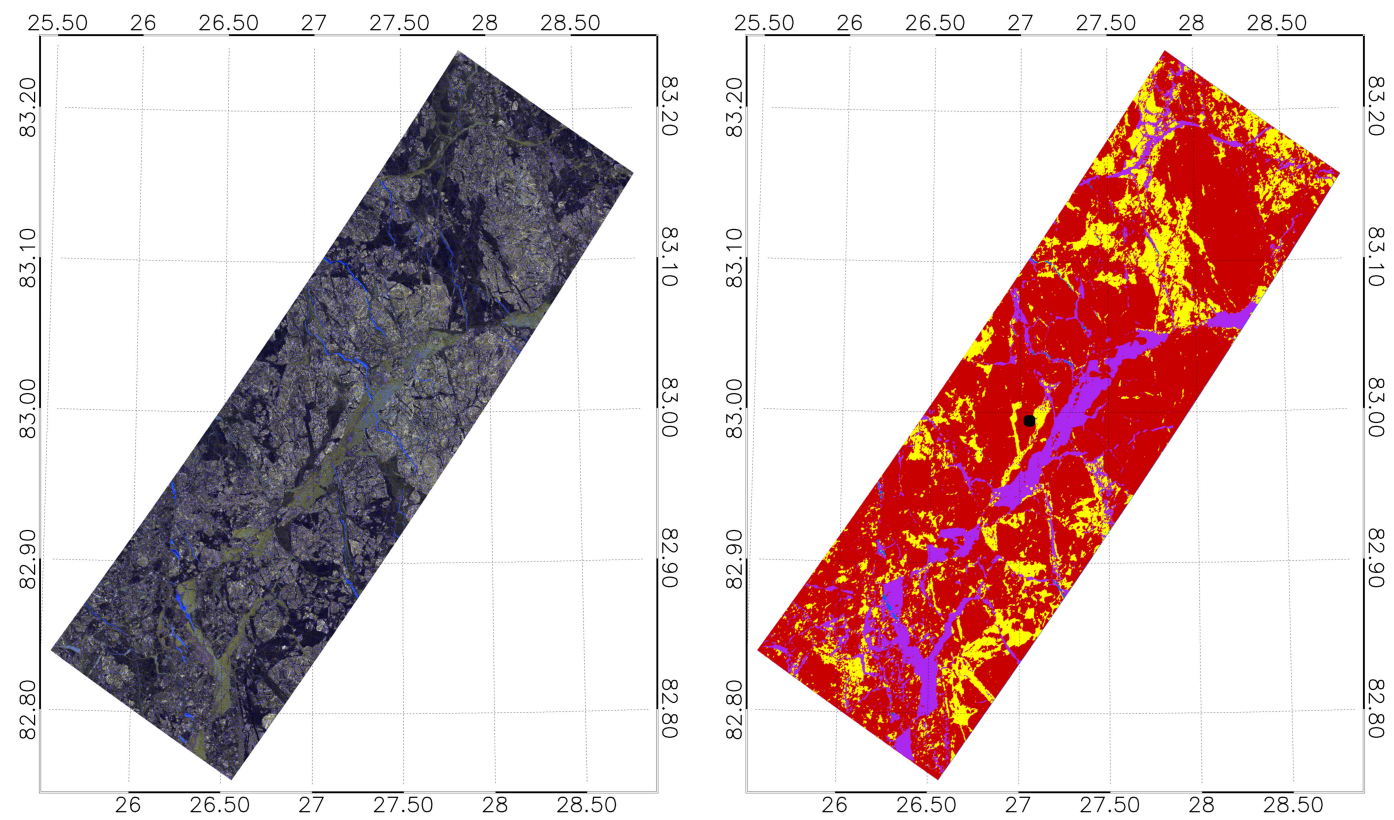

Fig. 11. Left: Geocoded RGB composite of the dual-polarimetric TSX acquisition on February 25, 2015. Right: Ice classification based on copol power ratio $\gamma$, geometric intensity $\mu$, scattering diversity $\delta$, surface scattering fraction $\tau$, span span, real copol cross product $\rho$, and local variances for each feature. Blue: OW/nilas, purple: YI, yellow: first-year ice (MFYI), red: rough first-year ice/multiyear ice (RFYMYI). Black dot marks position of RV Lance.
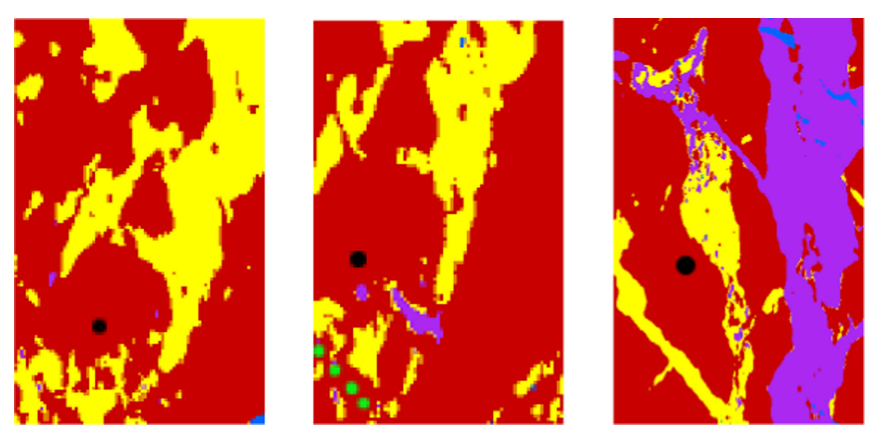

Fig. 12. Magnified subsections of classifications for February 07, 2015 (left image) and February 12, 2015 (center image) for the location of the first mooring of RV Lance, and for the second mooring (floe 2, right image) on February 25,2015$)$. Green dots in center image indicate location of refrozen lead. Blue: OW/nilas, purple: YI, yellow: first-year ice (MFYI), red: rough first-year ice/multiyear ice (RFYMYI). Black dot indicates position of RV Lance.

of dual-polarimetric TerraSAR-X data for automated sea ice classification. In our analysis, we utilized in situ information gathered during a field campaign with a high spatial and temporal correlation to the TS-X acquisitions of our work. In order to keep the computational overhead low, we performed a statistical analysis about the (nonlinear) correlation of the features and their relevance for sea ice classification. Based on this analysis, we arrived at the conclusion that, for our purposes, features involving eigendecomposition of the scatter coherency matrix $T_{P}$ do not provide informational benefit over features purely based on the covariance matrix $T_{L}$. The suggested ranking of features was then used to train a neural network classifier. Numerical and visual analysis of results are rather promising in terms of providing an operational ice chart for navigation. The three main ice classes plus OW were identified correctly in the majority of cases. The in situ data also confirm that the relative fraction of the four classes is realistic. It is important to note that the proposed method in principal can also be applied to quad-polarimetric SAR scenes subject to the training of a separate classifier. Future efforts will have to be devoted to refining the proposed methodology and testing our automated sea ice classification algorithm on a wider array of datasets. This encompasses the development of libraries of classifiers that are fine tuned to acquisition parameters such as incidence angle range, location, season, etc., depending on their variability. Likewise, we will also compare the performance of discussed polarimetric features from other sensors in different frequencies (e.g., Polarimetric C-band data from RADARSAT-2, L-band data from ALOS-2), compact polarimetry or other combinations of dual-polarimetric modes (e.g., HH-HV) in order to explore more comprehensively the ramifications of SAR polarimetry in the field of sea ice classification. The analysis of the feature quality can also be investigated by computing relevance and redundancy for different combinations of features and by computing classification accuracy results for such different subsets of features.

\section{ACKNOWLEDGMENT}

TerraSAR-X Images were acquired through DLR Science TS-X Data Proposal AO OCE 2082 (PI: Rudolf Ressel). The views, opinions, and findings contained in this paper are those of the authors and should not be construed as an official DLR position, policy, or decision.

The authors would like to thank the N-ICE2015 participants as well as the ship's crew of RV Lance for collecting the in situ data. 


\section{REFERENCES}

[1] C. M. Lee et al., "Marginal Ice Zone (MIZ) Program: Science and experiment plan," Applied Physics Laboratory, University of Washington, Seattle, WA, USA, Tech. Rep. APL-UW TR 1201, Oct. 2012.

[2] D. Hamidi, S. Lehner, T. König, and A. Pleskachevsky, "On the sea ice motion estimation with synthetic aperture radar," in Proc. TerraSAR-X Meeting Vortrags-Nr. CAL0166, 2011, pp. 1-10.

[3] J. Karvonen, "Operational SAR-based sea ice drift monitoring over the Baltic Sea," Ocean Sci., vol. 8, pp. 473-483, 2012.

[4] A. S. Komarov and D. G. Barber, "Sea ice motion tracking from sequential dual-polarization RADARSAT-2 images," IEEE Trans. Geosci. Remote Sens., vol. 52, no. 1, pp. 121-136, Jan. 2014.

[5] L. Kaleschke et al., "IRO-2 Eisvorhersage und Eisroutenoptimierung," Bundeswirtschaftsministerium für Wirtschaft und Technologie, Berlin, Germany, no. 22, 2013.

[6] R. Kwok, J. C. Curlander, R. McConnell, and S. S. Pang, "An icemotion tracking system at the Alaska SAR facility," IEEE J. Ocean. Eng., vol. 15 , no. 1 , pp. 44-54, 1990.

[7] A. K. Liu, B. Holt, and P. W. Vachon, "Wave propagation in the marginal ice zone: Model predictions and comparisons with buoy and synthetic aperture radar data," J. Geophys. Res., vol. 96, pp. 4605-4621, Mar. 1991.

[8] P. W. Vachon, F. M. Monaldo, B. Holt, and S. Lehner, "Ocean surface waves and spectra," in Synthetic Aperture Radar (SAR) Marine User's Manual, National Oceanic and Atmospheric Administration, Silver Spring, MD, USA, C. R. Jackson and J. R. Apel, Eds., 2004, pp. $139-169$.

[9] J. Karvonen, J. Vainio, M. Marnela, P. Eriksson, and T. Niskanen, “A comparison between high-resolution EO-based and ice analyst-assigned aea ice concentrations," IEEE J. Sel. Topics Appl. Earth Observ. Remote Sens., vol. 8, no. 4, pp. 1799-1807, Apr. 2015.

[10] W. Dierking and C. Wesche, "C-band radar polarimetry-Useful for detection of icebergs in sea ice?" IEEE Trans. Geosci. Remote Sens., vol. 52, no. 1, pp. 25-37, Jan. 2014.

[11] R. Ressel, A. Frost, and S. Lehner, "Navigation assistance for ice-infested waters through automatic iceberg detection and ice classification based on TerraSAR-X imagery," in Proc. 36th Int. Symp. Remote Sens. Environ., 2015, pp. 1049-1056.

[12] D. A. Clausi, "Comparison and fusion of co-occurrence, Gabor and MRF texture features for classification of SAR sea-ice imagery," AtmosphereOcean, vol. 39, pp. 183-194, 2000.

[13] D. A. Clausi and Y. Zhao, "Rapid extraction of image texture by cooccurrence using a hybrid data structure," Comput. Geosci., vol. 28 , no. 6, pp. 763-774, Jul. 2002. [Online]. Available: http://dx.doi.org/ 10.1016/S0098-3004(01)00108-X

[14] D. A. Clausi and Y. Zhao, "Grey level co-occurrence integrated algorithm (GLCIA): A superior computational method to rapidly determine co-occurrence probability texture features," Comput. Geosci., vol. 29 , no. 7, pp. 837-850, 2003. [Online]. Available: http://www. sciencedirect.com/science/article/pii/S009830040300089X

[15] D. A. Clausi and B. Yue, "Comparing cooccurrence probabilities and Markov random fields for texture analysis of SAR sea ice imagery," IEEE Trans. Geosci. Remote Sens., vol. 42, no. 1, pp. 215-228, Jan. 2004.

[16] S. Ochilov and D. Clausi, "Operational SAR sea-ice image classification," IEEE Trans. Geosci. Remote Sens., vol. 50, no. 11, pp. 4397-4408, Nov. 2012.

[17] N. Y. Zakhvatkina, V. Alexandrov, O. M. Johannessen, S. Sandven, and I. Frolov, "Classification of sea ice types in ENVISAT synthetic aperture radar images," IEEE Trans. Geosci. Remote Sens., vol. 51, pp. 2587-2600, May 2013

[18] A. V. Bogdanov, S. Sandven, O. M. Johannessen, V. Y. Alexandrov, and L. P. Bobylev, "Multisensor approach to automated classification of sea ice image data." IEEE Trans. Geosci. Remote Sens., vol. 43, no. 7, pp. 1648-1664, Jul. 2005.

[19] W. Dierking and L. T. Pedersen, "Monitoring sea ice using ENVISAT ASAR-A new era starting 10 years ago," in Proc. IEEE Int. Geosci. Remote Sens. Symp., Jul. 2012, pp. 1852-1855.

[20] R. Ressel and S. Lehner, "Texture-based sea ice classification on TerraSAR-X imagery," in Proc. 22 IAHR Int. Symp. ICE, 2014, pp. 503509.

[21] R. Ressel, A. Frost, and S. Lehner, "A neural network based classification for sea ice types on X-Band SAR images," IEEE J. Sel. Topics Appl. Earth Observ. Remote Sens., vol. 8, no. 7, pp. 3672-3680, Jul. 2015.
[22] S. Leigh, Z. Wang, and D. Clausi, "Automated Ice \#x2013;Water Classification Using Dual Polarization SAR Satellite Imagery," IEEE Trans. Geosci. Remote Sens., vol. 52, no. 9, pp. 5529-5539, Sep. 2014.

[23] R. Kwok, E. Rignot, B. Holt, and R. Onstott, "Identification of sea ice types in spaceborne synthetic aperture radar data," J. Geophys. Res., Oceans, vol. 97, no. C2, pp. 2391-2402, 1992. [Online]. Available: http://dx.doi.org/10.1029/91JC02652

[24] L.-K. Soh and C. Tsatsoulis, "Texture analysis of SAR sea ice imagery using gray level co-occurrence matrices," IEEE Trans. Geosci. Remote Sens., vol. 37, no. 2, pp. 780-795, Mar. 1999.

[25] J. Karvonen, M. Simila, and M. Makynen, "Open water detection from Baltic sea ice Radarsat-1 SAR imagery," IEEE Geosci. Remote Sens. Lett., vol. 2, no. 3, pp. 275-279, Jul. 2005

[26] Q. Yu, C. Moloney, and F. M. Williams, "SAR sea-ice texture classification using discrete wavelet transform based methods," in Proc. IEEE Geosci. Remote Sens. Symp., vol. 5, 2002, pp. 3041-3043.

[27] W. Dierking, H. Skriver, and P. Gudmandsen, "On the improvement of sea ice classification by means of radar polarimetry," in Proc. 23rd Symp. Eur. Assoc. Remote Sens. Lab., 2004, pp. 203-209.

[28] H. Wakabayashi, T. Matsuoka, K. Nakamura, and F. Nishio, "Polarimetric characteristics of sea ice in the sea of Okhotsk observed by airborne L-band SAR," IEEE Trans. Geosci. Remote Sens., vol. 42, no. 11, pp. 2412-2425, Nov. 2004.

[29] S. R. Cloude and E. Pottier, "An entropy based classification scheme for land applications of polarimetric SAR," IEEE Trans. Geosci. Remote Sens., vol. 35, no. 1, pp. 68-78, Jan. 1997.

[30] B. Scheuchl, R. Caves, I. Cumming, and G. Staples, "Automated sea ice classification using spaceborne polarimetric SAR data," in Proc. IEEE Geosci. Remote Sens. Symp., vol. 7, 2001, pp. 3117-3119.

[31] B. Scheuchl, I. Hajnsek, and I. Cumming, "Sea ice classification using multi-frequency polarimetric SAR data," in Proc. IEEE Geosci. Remote Sens. Symp., 2002, pp. 1914-1916.

[32] J. S. Lee, M. R. Grunes, and R. Kwok, "Classification of multi-look polarimetric SAR imagery based on complex Wishart distribution," Int. J. Remote Sens., vol. 15, no. 11, pp. 2299-2311, 1994. [Online]. Available: http://dx.doi.org/10.1080/01431169408954244

[33] M.-A. N. Moen, A. P. Doulgeris, S. N. Anfinsen, A. H. H. Renner, N. Hughes, S. Gerland, and T. Eltoft: Comparison of feature based segmentation of full polarimetric SAR satellite sea ice images with manually drawn ice charts, The Cryosphere, vol. 7, pp. 1693-1705, 2013, doi:10.5194/tc7-1693-2013

[34] M. A. N. Moen, S. Anfinsen, A. Doulgeris, A. Renner, and S. Gerland, "Assessing polarimetric SAR sea-ice classifications using consecutive day images," Ann. Glaciol., vol. 56, no. 69, p. 285-294, 2015.

[35] J. Praks, E. Koeniguer, and M. Hallikainen, "Alternatives to target entropy and alpha angle in SAR polarimetry," IEEE Trans. Geosci. Remote Sens., vol. 47, no. 7, pp. 2262-2274, Jul. 2009.

[36] H. Peng, F. Long, and C. Ding, "Feature selection based on mutual information criteria of max-dependency, max-relevance, and min-redundancy," IEEE Trans. Pattern Anal. Mach. Intell., vol. 27, no. 8, pp. 1226-1238, Aug. 2005.

[37] S. Nissen, "Neural Networks made simple," Tech. Rep. 2, 2005

[38] M. A. Granskog, P. Assmy, S. Gerland, G. Spreen, H. Steen, and L. H Smedsrud, "Arctic research on thin ice: Consequences of Arctic sea ice loss," Eos, vol., 97, 2016, doi:10.1029/2016EO044097.

[39] WMO Sea Ice Nomenclature, WMO/OMM/BMO 259-TP-145, suppl. 5 ed., World Meteorological Organization, Geneva, Switzerland, 1989.

[40] S. Voss, G. Heygster, and R. Ezraty, "Improving sea ice type discrimination by the simultaneous use of SSM/I and scatterometer data," Polar Res., vol. 22, no. 1, 2003. [Online]. Available: http://www. polarresearch.net/index.php/polar/article/view/6441

[41] C. Brekke, B. Holt, C. Jones, and S. Skrunes, "Discrimination of oil spills from newly formed sea ice by synthetic aperture radar," Remote Sens. Environ., vol. 145, pp. 1-14, 2014. [Online]. Available: http:// www.sciencedirect.com/science/article/pii/S0034425714000285

[42] B. B. Thomsen, S. Nghiem, and R. Kwok, "Polarimetric C-band SAR observations of sea ice in the Greenland Sea," in Proc. IEEE Int. Geosci. Remote Sens. Symp., 1998, pp. 2502-2504.

[43] L. E. B. Eriksson, K. Borenäs, W. Dierking, A. Berg, M. Santoro, P. Pemberton, H. Lindh, and B. Karlson, "Evaluation of new spaceborne SAR sensors for sea-ice monitoring in the Baltic Sea," Can. J. Remote Sens., vol. 36, p. 56, Jan. 2010. 
[44] S. Skrunes, C. Brekke, and T. Eltoft, "Characterization of Marine Surface Slicks by Radarsat-2 Multipolarization Features," IEEE Trans. Geosci. Remote Sens., vol. 52, no. 9, pp. 5302-5319, Sep. 2014.

[45] L. Yu and H. Liu, "Feature selection for high-dimensional data: A fast correlation-based filter solution," in Proc. 20th Int. Conf. Mach. Learn., 2003, pp. 856-863.

[46] T. Geldsetzer and J. J. Yackel, "Sea ice type and open water discrimination using dual co-polarized C-band SAR," Can. J. Remote Sens., vol. 35, no. 1, pp. 73-84, 2009. [Online]. Available: http://dx.doi.org/10.5589/m08-075

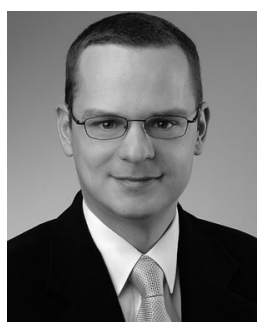

Rudolf Ressel received the Diploma degree in mathematics from the Georg-August-University, Göttingen, Germany, in 2008, and the Ph.D. degree in mathematics from the University of Bremen, Bremen, Germany, in 2012, in the field of inverse problems.

He joined the German Aerospace Center (DLR), Bremen, in July 2013, where he works as a Scientific Assistant with the Maritime Safety and Security Lab. His main research interests include ice type classification by means of SAR image analysis.

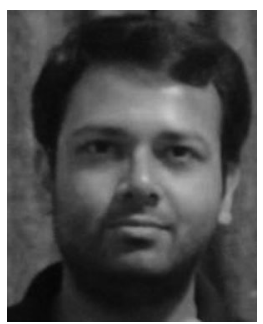

Suman Singha (M'15) received the M.Tech. degree in remote sensing from the Indian Institute of Technology, Roorkee, India, in 2009, and the M.Sc. degree in remote sensing and Ph.D. degree in microwave remote sensing from the University of Hull, Kingston upon Hull, U. K., in 2010 and 2014, respectively.

$\mathrm{He}$ was a Visiting Scientist with the European Maritime Safety Agency, Portugal, during his doctoral studies. Since 2013, he has been with the Maritime Safety and Security Lab., German Aerospace Center, Bremen, Germany, as a Research Scientist. His research interests include the application of artificial intelligence and machine vision approaches to classify traditional and polarimetric SAR images with emphasis on oil spill detection and sea ice classification.

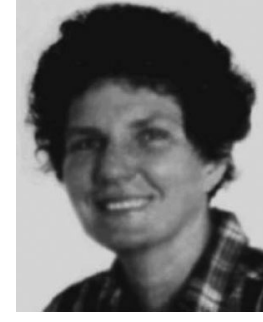

Susanne Lehner (M'01) received the M.Sc. degree in applied mathematics from Brunel University, Uxbridge, U.K., in 1979, and the Ph.D. degree in geophysics from the University of Hamburg, Hamburg, Germany, in 1984.

She was a Research Scientist with the Max-Planck Institute for Climatology, Hamburg, and joined the German Aerospace Center, Wessling, Germany, in 1996. She is currently a Group Leader of the Maritime Security Research Center, Remote Sensing Technology Institute, German Aerospace Center, Bremen, working on the development of algorithms determining marine parameters from synthetic aperture radars.

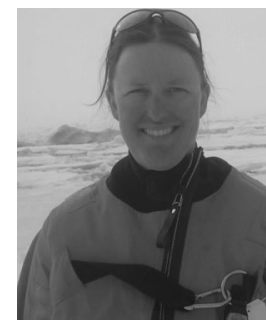

Anja Rösel received the Ph.D. degree from the University of Hamburg, Hamburg, Germany, in 2012.

She is currently a Postdoctoral at the Norwegian Polar Institute, Troms $\varnothing$, Norway and involved in the N-ICE2015 project. Her research interests include sea ice, snow mass balance from observations, and remote sensing of sea ice. At University of Hamburg, she focused on melt pond detection from optical satellite data.

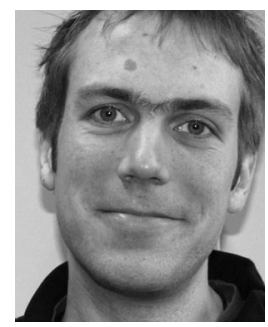

Gunnar Spreen (M'08) received the Diploma degree in physics (comparable M.Sc.) in 2004 and the $\mathrm{Ph}$.D. degree in oceanography in 2008 , both from the University of Hamburg, Hamburg, Germany.

$\mathrm{He}$ works on satellite remote sensing of sea ice with focus on monitoring changes of sea ice (extent, mass, and dynamics) and on understanding underlying climate processes in polar regions. He is currently leading the Junior Research Group for remote sensing of sea ice at the University of Bremen, Bremen, Germany. Before, he was a Research Scientist at the Norwegian Polar Institute and a Postdoctoral Scholar at the Jet Propulsion Laboratory, California Institute of Technology, Pasadena, CA, USA. 